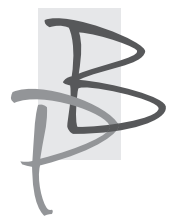

Jarosław Ławski*

Uniwersytet w Białymstoku

https://orcid.org/0000-0002-1167-5041

\title{
Międzynarodowa Konferencja Naukowa „Naukowe i literackie światy Zygmunta Glogera. Piśmiennictwo - historia - etnografia - ethos ziemiański - język", Białystok, 20-21 XI 2019 roku. Sprawozdanie
}

Przypomnijmy rzecz oczywistą tylko na pozór - od 2013 roku Białystok stał się głównym ośrodkiem badawczym myśli i twórczości Zygmunta Glogera, sławnego od ponad stu lat autora Encyklopedii staropolskiej ilustrowanej (t. I-IV, 1900-1903). Stało się tak za sprawą grantu Naukowego Programu Rozwoju Humanistyki pod nazwą „Naukowa edycja krytyczna Pism rozproszonych Zygmunta Glogera w trzech tomach" (2013-2017), realizowanego przez Dział Naukowy Książnicy Podlaskiej. Jego plonem stały się monumentalna edycja Pism rozproszonych Glogera w III tomach ${ }^{1}$ oraz monografia zbiorowa poświęcona badaczowi i pisarzowi². W związku z tym grantem zainaugurowano również cykl konferencji pod nazwą „Zygmunt Gloger. Pisarz, myśliciel, uczony", z których pierwsza odbyła się w roku $2015^{3}$.

* Jarosław Ławski - prof. dr hab., badacz literatury XIX-XXI wieku, kierownik Katedry Badań Filologicznych „Wschód-Zachód” na Wydziale Filologicznym Uniwersytetu w Białymstoku. Autor monografii, m.in. Mickiewicz - Mit - Historia. Studia (Białystok 2010); Miłosz: „Kroniki” istnienia. Sylwy (Białystok 2014).

1 Zob. Z. Gloger, Pisma rozproszone, T. I-III, red. naukowa edycji J. Ławski, J. Leończuk, Białystok 2014-2016. Pomysłodawcą badań nad Glogerem i edycji dzieł był dyrektor Książnicy Podlaskiej Jan Leończuk, zaś grantem kierował prof. Jarosław Ławski.

2 Por. Zygmunt Gloger. Pisarz, myśliciel, uczony. Studia, red. J. Ławski, J. Leończuk, Ł. Zabielski, Białystok 2016, ss. 368.

3 Zob. sprawozdanie z sesji poprzedniej: S. Kochaniec, Ł. Zabielski, I Ogólnopolska Konferencja Naukowa ,Zygmunt Gloger 1845-1910. Pisarz, myśliciel, uczony. Rewizje”. Biatystok (23-24 X 2015). Sprawozdanie, „Bibliotekarz Podlaski”, nr 31/2015, s. 235-240. 


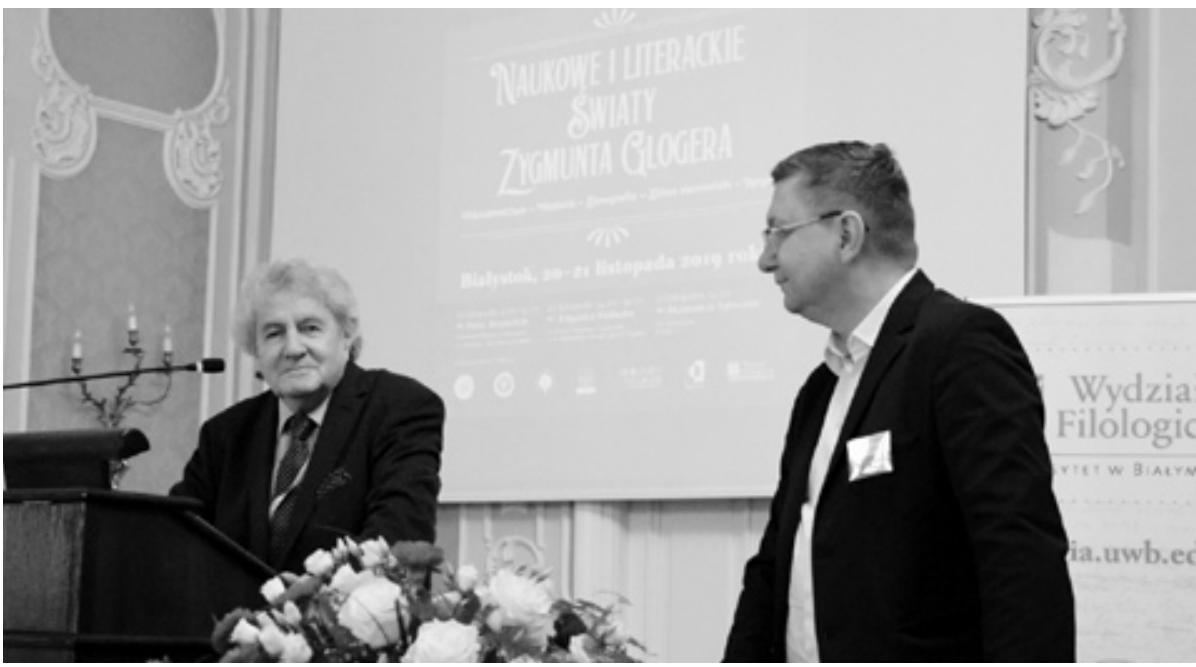

Inauguracja w Pałacu Branickich. Od lewej: prof. Lucjan Suchanek (PAU, Kraków), prof. Jarosław Ławski (UwB, Białystok)

Fot. B. Maleszewska-Oksztol (Książnica Podlaska)

Kiedy w 2018 roku Książnica Podlaska otrzymała kolejny grant edytorski pod nazwą „Kontynuacja krytycznej edycji Pism Zygmunta Glogera w VII tomach" (2018-2021), stało się jasne, iż również spotkania sesyjne będą kontynuowane. II Międzynarodowa Konferencja Naukowa z cyklu „Zygmunt Gloger. Pisarz, myśliciel, uczony”, zatytułowana „Naukowe i literackie światy Zygmunta Glogera. Piśmiennictwo - historia - etnografia - ethos ziemiański - język" obradowała w Białymstoku i Tykocinie w dniach 20-21 listopada 2019 roku. Tym razem głównymi współorganizatorami przedsięwzięcia były: Wydział Filologiczny Uniwersytetu w Białymstoku, Polska Akademia Umiejętności i Książnica Podlaska im. Łukasza Górnickiego. Współpraca z Wydziałem I Filologicznym PAU, jaką rozwija Katedra Badań Filologicznych „Wschód - Zachód” UwB, zaowocowała także tym razem obecnością i na sesji, i w komitetach naukowych przedstawicieli tej niezmiernie elitarnej instytucji naukowej.

Warto podkreślić też dobroczynną rolę partnerów Konferencji: Uniwersytetu Medycznego w Białymstoku, który na korzystnych warunkach użyczył Auli w Pałacu Branickich, a także Muzeum w Tykocinie, które przyjęło pod swój dach uczestników sesji w czasie drugiego, objazdowego dnia obrad. 


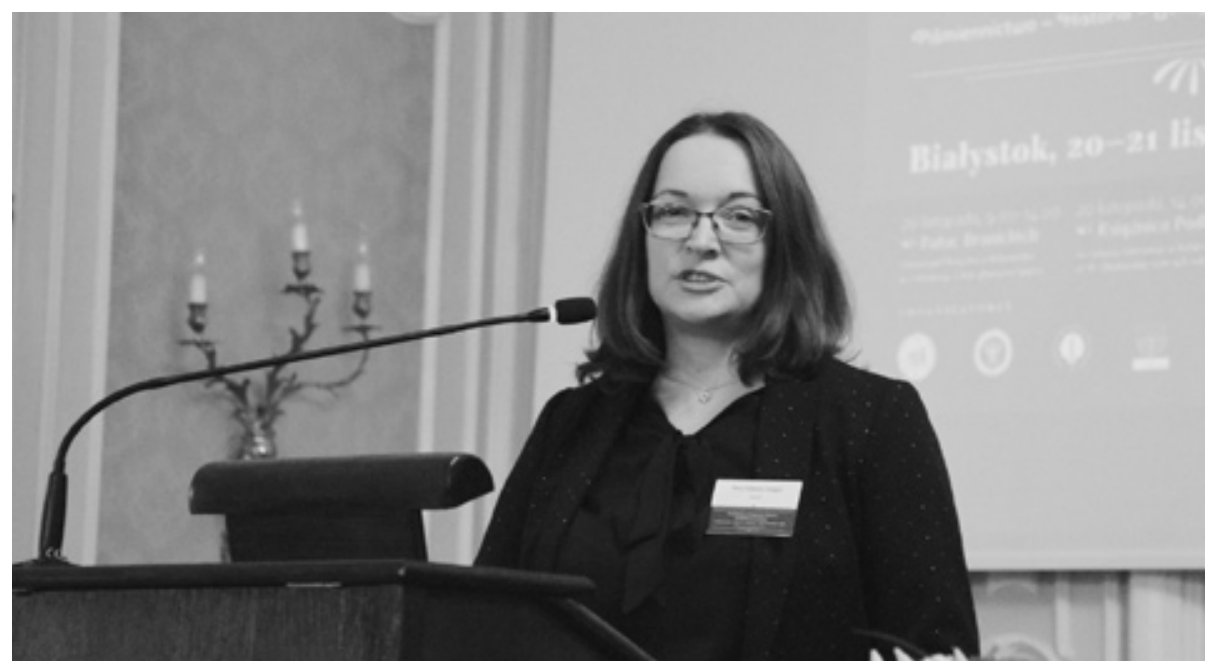

Obrady plenarne w Pałacu Branickich, 20 XI 2019 r.

Na zdjęciu: pani Liliana Gloger (Szczytno), prawnuczka Zygmunta Glogera

Fot. B. Maleszewska-Oksztol (Książnica Podlaska)

Komitet Naukowy Konferencji ${ }^{4}$ złożony był głównie z przedstawicieli Rodziny Glogerów oraz profesorów PAU, Uniwersytetu Jagiellońskiego i UwB. Przewodniczyli mu prof. Lucjan Suchanek (PAU) oraz prof. Irena Szczepankowska (UwB). Z kolei Komitetowi Organizacyjnemu ${ }^{5}$ szefował prof. Jarosław Ławski. Jego zastępczynią była dyr. Jolanta Gadek z Książnicy Podlaskiej oraz trzech sekretarzy z tejże instytucji: dr Łukasz Zabielski, dr Michał Siedlecki i dr Kamil K. Pilichiewicz. Uczesnicy sesji podjęli następujące zagadnienia badawcze:

4 W skład Komitetu Naukowego weszli ponadto: prof. Kamila Budrowska - Uniwersytet w Białymstoku; prof. Bogusław Dopart - Uniwersytet Jagielloński; prof. Halina Krukowska - Uniwersytet w Białymstoku; pani Liliana Gloger - Szczytno; prof. Julian Maślanka - PAU, Uniwersytet Jagielloński; prof. Violetta Wejs-Milewska - Uniwersytet w Białymstoku; prof. Anna Wydrycka - Uniwersytet w Białymstoku; prof. Kazimierz Korus - PAU. Wydział I Filologiczny; pani Magdalena Zawidzka-Kwiatkowska - Warszawa.

5 W Komitecie Organizacyjnym pracowali także: dr hab. Anna Janicka, prof. UwB ZFBI, Kolegium Literaturoznawstwa; dr Krzysztof Korotkich - KBF „Wschód - Zachód”, dr Marcin Bajko - KBF „Wschód - Zachód”; dr Anna Maroń - Kolegium Literaturoznawstwa UwB; mgr Irena Szewczenko - ZFBI, Wydział Filologiczny UwB; mgr Joanna Godlewska Uniwersytet w Białymstoku; mgr Bożena Poniatowicz - Uniwersytet w Białymstoku. 


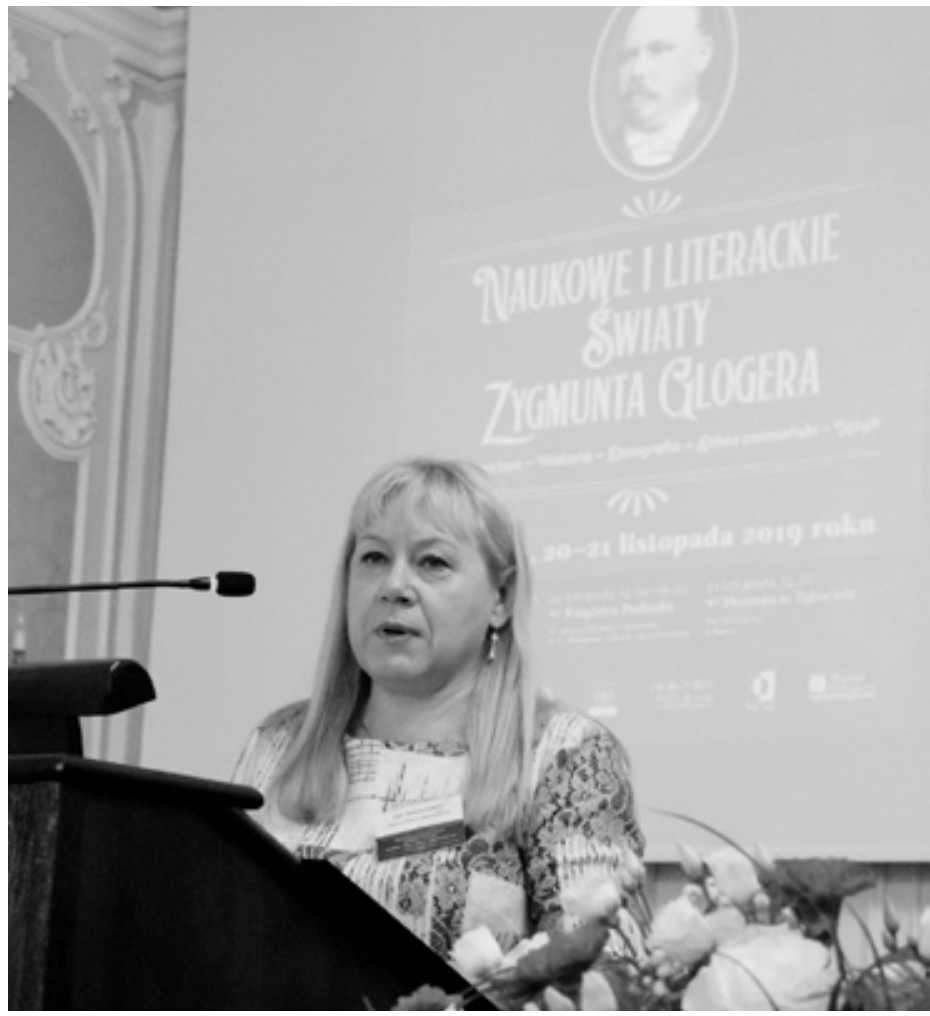

Pierwszy dzień Konferencji. Na zdjęciu dyr. Jolanta Gadek (Książnica Podlaska) Fot. Bogumiła Maleszewska-Oksztol (KP, Białystok)

- Gloger jako przykład XIX-wiecznego naukowca i literata, piśmiennika i publicysty.

- Naukowe pasje Glogera: historia, archeologia, etnografia, folklorystyka, geografia, historia sztuki, języko- i literaturoznawstwo (i inne).

- Metodologia prac Glogera.

- Świat ziemiański z pogranicza Wielkiego Księstwa Litewskiego i Korony Królestwa Polskiego.

- Rodzina Glogerów: genealogia, tradycje, pamięć rodu, kontakty z innymi rodzinami ziemiańskimi.

- Gloger wobec narodów Europy Środkowo-Wschodniej: Litwinów, Białorusinów, Ukraińców, Niemców, Rosjan i innych; wpływ Glogera na te kultury. 
- Encyklopedia staropolska ilustrowana jako XIX-wieczna summa wiedzy o Rzeczypospolitej Obojga Narodów: aktualność, rewizje haseł, tradycja gatunkowa.

- Gloger jako kolekcjoner.

- Wyobrażenia o świecie i przemianach cywilizacyjnych w pismach Glogera.

- Dzieła Glogera w przekładach na inne języki i w wydaniach zagranicznych.

- Rola ilustracji, grafiki, fotografii w pracach twórcy z Jeżewa; Gloger-rysownik.

- Kategorie „ludu”, „narodu”, „państwa” w myśli pisarza i refleksji XIX-wiecznego ziemiaństwa.

- Staropolskie silvae rerum w pismach i myśli Glogera oraz ich tradycja w świecie XIX-wiecznego ziemiaństwa.

- Glogerowskie „miejsca”: Jeżewo, Tykocin, Białystok, Grodno, Warszawa, Kraków i inne.

- Swoistość dorobku Glogera na tle przedstawicieli innych nauk humanistycznych i społecznych XIX wieku; twórczość Glogera w ujęciu metod interpretacyjnych współczesnej humanistyki; Gloger na tle XXI-wiecznych ujęć nowożytności i symptomów nowoczesności.

- Recepcja naukowa i literacka pism Glogera od XIX wieku po współczesność.

W Konferencji wzięło udział 30 czynnych uczestników z Polski, Ukrainy, Białorusi, Austrii i Węgier. Co należy podkreślić - po raz pierwszy badaniom nad Glogerem udało się nadać charakter międzynarodowy! Sesję otworzył prof. Jarosław Ławski (UwB), po którym głos zabrali prof. Lucjan Suchanek i dyr. Jolanta Gadek, podkreślając rangę białostockich badań nad Glogerem. Tradycją tych badań stała się współpraca zespołu naukowców z Rodziną Glogerów, którą na sesji w 2015 roku reprezentowała Pani Magdalena ZawidzkaKwiatkowska, prawnuczka ${ }^{6}$, a także Marcin i Aleksander Kozubowscy.

6 Jest ona potomkinią córki Glogera, Janiny. W czasie Konferencji z 2015 roku odbyło się z nią (23 X, godz. 18.00) specjalne spotkanie w Książnicy Podlaskiej. Por. wywiad: G. Kowalski, Pradziadek Zygmunt Gloger. Rozmowa z Magdalena Zawidzka-Kwiatkowska, „Bibliotekarz Podlaski” 1/2017, s. 133-140. 


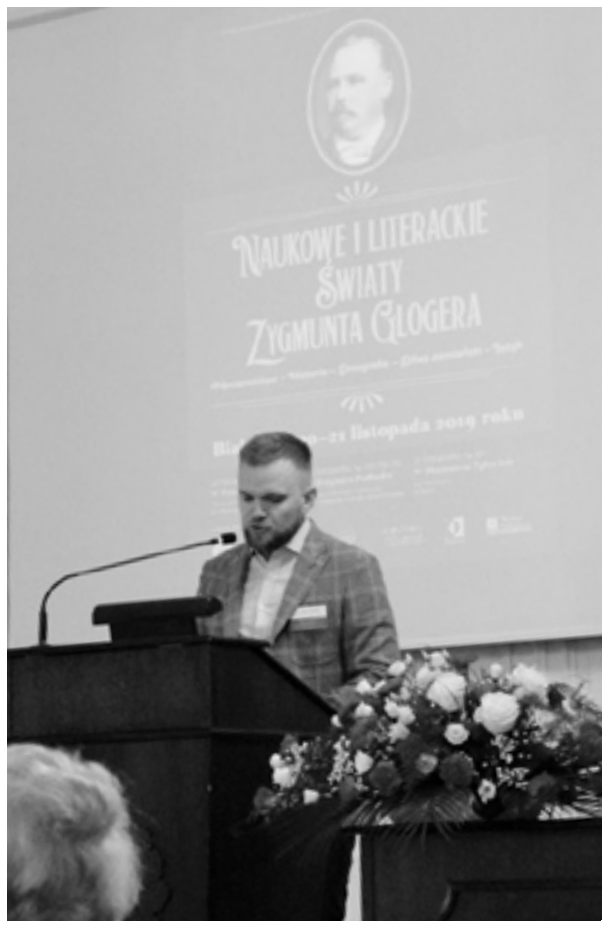

Dr Łukasz Zabielski (Dział Naukowy, Książnica Podlaska) Fot. Bogumiła Maleszewska-Oksztol (Książnica Podlaska)

W 2019 roku uroczystego otwarcia Konferencji dokonała Pani Lilliana Gloger ze Szczytna, reprezentująca inną, od syna pisarza się wywodzącą linię rodu? . W Białymstoku towarzyszył jej praprawnuk Glogera - Jej syn Kamil Banul. W czasie pięciogodzinnych obrad w Pałacu Branickich wygłoszono dziewięć referatów:

- Mgr Liliana Gloger (Szczytno), Z dziejów rodu Glogerów: linia syna Zygmunta Glogera - Stanistawa;

- Dr hab. Urszula Kowalczuk (UW, Warszawa), Biografia i metoda. Zygmunt Gloger o Julianie Bartoszewiczu;

- Prof. dr hab. Lucjan Suchanek (PAU, Kraków), Zygmunt Gloger i folklorystyka rosyjska jego czasów;

7 Zob. J. Ławski, ,...od najmłodszych lat pamiętam książki jego autorstwa $w$ domowej bibliotece...” Rozmowa z Liliana Gloger, „Bibliotekarz Podlaski” 1/2017, s. 141-148. 
- Doc. dr Mikołaj Chmialnicki (BGU, Mińsk), Pisarze pogranicza białorusko-polskiego w pracach Zygmunta Glogera;

- Prof. dr hab. Henryka Ilgiewicz (Uniwersytet Wileński, Litwa), Udziat ziemiaństwa $w$ wileńskich towarzystwach naukowych na przelomie XIX-XX w.;

- Prof. dr hab. Rościsław Radyszewski (Uniwersytet Kijowski, Ukraina), Pogranicze ukraińsko-polskie w ,Encyklopedii staropolskiej” Zygmunta Glogera;

- Prof. Swietłana Musijenko (Uniwersytet Grodzieński, Białoruś), Zygmunt Gloger w przestrzeni estetycznej Biatorusi;

- Prof. Joanna Okoniowa (IJP PAN, Kraków; PWSZ w Tarnowie), prof. Jan

Okoń (Kraków), Zygmunt Gloger jako stownikarz (wprowadzenie do edycji ,Dopetnień” do ,Stownika gwary tykocińskiej”);

- Dr hab. Dorota Rembiszewska, prof. IS PAN (Warszawa), Sprawy uczonego ziemianina - listy Zygmunta Glogera do Jana Karłowicza.

Ujmującym akcentem inauguracji stało się niezapowiadane przemówienie prof. Jana Okonia (Kraków), który zaprezentował uczestnikom pierwsze pełne wydanie słownika gwary tykocińskiej Glogera ${ }^{8}$, poszerzone o materiały rękopiśmienne wydobyte z Biblioteki UJ. Współautorką tej publikacji, która dopiero co opuściła drukarnię, jest prof. Joanna Okoniowa z Instytutu Języka Polskiego PAN w Krakowie.

Po półtoragodzinnej przerwie obradowano w dwóch zespołach w salach Książnicy Podlaskiej. Sekcja I analizowała Konteksty literackie ${ }^{9}$, z kolei Sekcja II badała Język, historię, kulturę ${ }^{10}$. W sumie wystąpiło w tej części sesji 17 badaczy. Dzień zakończyła kolacja w sali galerii Książnicy.

8 Por. J. Okoniowa, J. Okoń, Zygmunta Glogera ,Stownik gwary ludowej w okręgu tykocińskim”. Dopetnienia, Kraków: Collegium Columbinum 2019.

9 W tej części wysłuchano m. in. wystąpień:

- dr hab. Violetta Wróblewska, prof. UMK (Toruń), Bajki Zygmunta Glogera w systematyce watków Juliana Krzyżanowskiego;

- prof. Jarosław Ławski (UwB, PAU), Gloger wobec idei niepodległości Polski;

- dr hab. Anna Janicka, prof. UwB (Białystok), Jeden rys do obrazu kobiety u Glogera;

- dr Marta Kacprzak (BUW, Warszawa), Publikacje Zygmunta Glogera w warszawskich czasopismach z lat 1905-1910 a sprawa oświaty w Królestwie Polskim.

10 W Sekcji II zaprezentowano $m$. in. referaty:

- doc. dr Paweł Nawojczyk (BGU, Mińsk, Białoruś), Спадчына 3. Глогера і культурнаасветніцикая дзейнасиьь нашаніуциай; 
Drugiego dnia obrad (czwartek 20 XI) badacze o godz. 8.30 udali się na objazd miejsc związanych z życiem i twórczością Glogera. Przewodnikiem była mgr Izabela Szymańska (PTTK, Książnica Podlaska), która - pomimo dżdżystej pogody, wichru i chłodu - dzielnie i ze szczegółami opowiadała gościom o pokazywanych miejscach. A były to: letnia rezydencja Branickich w Choroszczy, ruiny browaru Glogerów w Jeżewie, zabytki miasta Tykocina, w tym Synagoga, oglądana już po zmroku cmentarna kaplica Glogerów na tykocińskim cmentarzu, pod którą zapalono znicz. Około południa rozpoczęła się też w Muzeum w Tykocinie sesja naukowa, wyjazdowa, której przewodniczył dr hab. Artur Bracki z Kijowskiego Uniwersytetu im. Borisa Hrinczenki. Przedstawiono następujące referaty:

- Dr hab. Maciej Karczewski (UwB, Białystok), Zygmunt Gloger. Starożytnik czy archeolog?;

- Dr hab. Andrzej Borkowski (UPH, Siedlce), Obraz kultury literackiej Polski przedrozbiorowej w ,Encyklopedii staropolskiej” Zygmunta Glogera;

- Dr Łukasz Zabielski (Książnica Podlaska), Światy Zygmunta Glogera: o budowaniu w przestrzeni napięć.

Po dość burzliwej dyskusji uczestnicy Konferencji udali się na obiad do restauracji w Tykocinie. Należy wyrazić wielkie uznanie dyr. Andrzejowi Lechowskiemu i dyr. Januszowi Sękowskiemu, którzy zgodzili się na bezpłatne użyczenie pomieszczeń swych muzeów. Niezapomnianą narrację historyczną o Żydach z Tykocina stworzył w Synagodze Pan Dariusz Szada-Borzyszkowski, z pasją opowiadający o życiu i wymordowaniu społeczności żydowskiej, także o losach Synagogi jako znanego na całym świecie obiektu muzealnego. Wzorowo pracę sekretarzy sesji koordynował dr Łukasz Zabielski.

Konferencja poprzedziła edycję kolejnych siedmiu tomów pism Glogera.

Zgodzono się, iż należy go badać na tle jego własnej epoki, a wtedy najpełniej uwidacznia się prekursorstwo jego prac archeologicznych, literackich, folklorystycznych (takie tezy zaprezentowali: dr hab. Violetta Wróblewska,

- dr hab. Artur Bracki (UG, Uniwersytet im. R. Hrinczenki w Kijowie), Dzieła Zygmunta Glogera jako dorobek etnografa-podróżnika (wymiar transkulturowy);

- mgr Patryk Suchodolski (Książnica Podlaska im. Ł. Górnickiego), Tradycja, historia, postęp - Zygmunt Gloger wobec wizji dziejów Aleksandra Świętochowskiego;

- Péter Fülöp Nagy (Uniwersytet Wiedeński), Zygmunt Gloger i Kongres Antropologiczno-Archeologiczny w Budapeszcie w 1876 roku. 
prof. UMK, dr Łukasz Zabielski i dr hab. Maciej Karczewski). Konferencja wzbudziła zainteresowanie TVP Białystok i mediów internetowych. Obradom w Pałacu Branickich przysłuchiwali się tym razem niezbyt liczni uczniowie białostockich liceów, obecni za to byli studenci białoruskiej filologii.

Nade wszystko jednak ugruntowano przekonanie, że Zygmunt Gloger jest jedną z najważniejszych postaci kultury polskiej XIX wieku. Należy mieć nadzieję, że prace nad jego spuścizną podsumuje w przyszłości III Konferencja $\mathrm{z}$ tego cyklu, tym razem już w całości, jak zapowiedziano, poświęcona jego opus magnum, to jest Encyklopedii staropolskiej ilustrowanej ${ }^{11}$.

Uczestnicy Konferencji wieczorem, w czwartek 21 listopada, wracali z Tykocina być może nieco zziębnięci, lecz na pewno z przekonaniem, że warto było zanurzyć się w świat Glogera, świat podlaskiej prowincji, którą ten wybitny człowiek uczynił swoim własnym centrum świata. I zrobił to bez kompleksu prowincjalności.

11 Uczestnicy Konferencji wyraźnie artykułowali postulat nowej krytycznej edycji Encyklopedii staropolskiej, wykorzystującej możliwości Internetu, technik cyfrowych i współczesną wiedzę, a także szerokie, interdyscyplinarne podejście. 